\title{
A arte do disfarce: BNCC como gestão e regulação do currículo
}

\section{The art of disguise: BNCC as curriculum management and regulation El arte del disfraz: BNCC como gestión y regulación del currículo}

\section{LUIZ FERNANDES DOURADO ROMILSON MARTINS SIQUEIRA}

\begin{abstract}
Resumo: O presente artigo parte de uma tese central que orienta suas reflexões críticas sobre a Base Nacional Comum Curricular (BNCC). Trata-se de compreendê-la como uma política que articula processos de gestão, avaliação e regulação do currículo, com clara ênfase na retórica da mudança e da reforma do conhecimento. O pressuposto que orienta esta tese parte do entendimento de que vivenciamos um discurso e/ou retórica neo economicista e reformista em torno da proposição e materialização desta política cuja materialização e concretude poderá implicar em retrocessos na gestão democrática e na autonomia dos sistemas e instituições educativas, nas dinâmicas curriculares, nos processos formativos e na autonomia docente.
\end{abstract}

Palavras-chave: Avaliação, currículo, Bncc, gestão e regulação.

Abstract: The present article comes from a central thesis that guides its critical reflections on the National Curricular Common Base (BNCC). It seeks to understand BNCC as a policy that articulates processes of management, evaluation, and regulation of the curriculum, emphasizing the rhetoric of change and knowledge reform. The assumption that guides this theory starts from the understanding that we are experiencing a rhetorical and/or neo economicist and reformist discourse about the proposition and materialization of this policy whose materialization and concretization may be implicit in the setbacks in democratic management and in the autonomy of educational systems and institutions, curricular dynamics, formative processes, and teacher autonomy.

Keywords: Evaluation, curriculum, BNCC, management and regulation.

Resumen: Este artículo se basa en una tesis central que guía sus reflexiones críticas sobre la Base Nacional Común Curricular (BNCC). Se trata de comprenderla como una política que articula los procesos de gestión, evaluación y regulación del currículo, con un claro énfasis en la retórica del cambio y la reforma del conocimiento. La hipótesis que orienta esta tesis se basa en el entendimiento de que estamos vivenciando un discurso y/o retórica neo economicista y reformista acerca de la proposición y materialización de esta política cuya materialización y concreción podrá implicar regresiones en la gestión democrática y en la autonomía de los sistemas e instituciones educativos en las dinámicas curriculares, en los procesos formativos y en la autonomía docente.

Palabras clave: Evaluación, currículo, BNCC, gestión y regulación. 


\section{INTRODUÇÃO}

Tenho usado a frase epistemologia social referindo-me à linha de análise que orienta este estudo: a relação do conhecimento, instituições e poder. Uso epistemologia como um conceito histórico, social e pragmático (...) procuro analisar a inter-relação da mente com as condições materiais e não considerá-las como 'dualistas'. Além disso, tenho procurado postular uma teoria do conhecimento como uma teoria histórica da sociedade e da individualidade (...) não há base comum onde possamos colocar um verdadeiro consenso ou um modelo neutro permanente (...) não há esquemas universais de raciocínio e racionalidade, mas somente epistemologias socialmente construídas que representam e incorporam relações sociais. (POPKEWITZ, 1997, p. 39)

A discussão e o complexo processo de aprovação pelo Conselho Nacional de Educação, bem como de homologação de Base Nacional Comum Curricular (BNCC), pelo ministério da educação (MEC), efetivaram-se a partir de proposta do MEC que resultou na segmentação da Educação Básica, expressa pela aprovação de duas bases curriculares: uma para a Educação Infantil e o Ensino Fundamental e outra, direcionada ao ensino médio. Todo esse movimento marcou, ainda, a secundarização das Diretrizes Curriculares Nacionais para a Educação Básica.

É preciso compreender esse processo no bojo das novas orientações e processos de gestão, avaliação e regulação da educação e do currículo, expressos por meio da ênfase na retórica da mudança e da reforma do conhecimento. O pressuposto que orienta esta tese parte do entendimento de que vivenciamos um discurso e/ou retórica 'neoeconomicista' e 'reformista' em torno da proposição e materialização desta política. Portanto, o tema é tratado aqui a partir do ponto de vista dialético em seus limites e possibilidades, seus equívocos e potencialidades, sua retórica e concretude.

Um destaque importante a ser considerado se refere ao papel do Estado na condução da BNCC como política nacional. Nesse sentido, há que se destacar aquilo que se configurou a partir da década de 1990, que, dentre outros processos, "as políticas públicas passam a ser orientadas por uma reforma de Estado, que engendra alterações substantivas nos padrões de intervenção estatal, redirecionando as formas de gestão e, consequentemente, as políticas públicas, particularmente, as políticas educacionais". (DOURADO, 2013, p. 368) Nesse sentido, destaca-se que 
o Estado não é apenas mediação nas relações de classe e elemento de preservação do predomínio de uma sobre a outra classe. $\mathrm{Na}$ época de conversão da estrutura econômica, como se verifica no Brasil, nas últimas décadas, o Estado surge como agente do processo produtivo. Ele opera, também e principalmente, no nível infraestrutural, diretamente no processo de formação do capital, isto é, de acumulação capitalista. Na medida em que o processo produtivo, em sentido amplo, exprime a forma pela qual se organiza e cristaliza a práxis coletiva, segundo as determinações do mercado, o poder público participa intensamente na formulação das possibilidades e na própria dinamização das forças produtivas. [...] Nesse sentido, o Estado é a expressão das relações de apropriação e dominação. (IANNI, 2004 , p. 240).

O agravamento dessas relações de apropriação e dominação descritas por Ianni (2004) ganharam maiores contornos nos últimos anos. Assim,

Após a aprovação do PNE ${ }^{1}$ 2014-2024 (BRASIL, 2014), e na esteira do golpe parlamentar que rompe com a legalidade democrática no Brasil, no momento que deveria ser o de materialização do Plano, passamos a ter retrocessos significativos na agenda e nas políticas públicas, especialmente nas políticas educacionais, envolvendo as temáticas do financiamento, avaliação, gestão, currículo e formação de professores. De modo geral, observa-se uma contrarreforma, bastante conservadora e privatista, no campo da educação, por meio de amplo processo de (des)regulação que favorece a expansão privada mercantil. A orientação e lógica mercantil se fazem presentes e predominantes nos instrumentos legais e nas ações e programas produzidos, da creche à pós-graduação.” (DOURADO; OLIVEIRA, 2018, p. 40)

É nesse campo de tensão que se efetivou o debate sobre a BNCC. A aprovação desse documento no Conselho Nacional de Educação (CNE) também

1 O novo PNE promulgado por meio da Lei no. 13.005/2014, traz metas e estratégias sobre as diversas questões que envolvem a necessidade de se unir esforços federativos para a institucionalização efetiva do Sistema Nacional de Educação (SNE) que expresse projeto de nação. Neste sentido, “o PNE, especialmente nas Metas 2, 3 e 7 - estratégias 2.1; 3.2 e 7.1, respectivamente, indicam a atribuição do MEC, em articulação com os estados, Distrito Federal e municípios, de encaminharem ao $\mathrm{CNE}$ diretrizes pedagógicas para a Educação Básica e a base nacional comum dos currículos, respeitadas a diversidade regional, estadual e local. privilegia uma centralidade de um Documento cuja lógica e dinâmica pedagógica atenta para os objetivos de aprendizagem descolados do desenvolvimento, como definido no PNE. Outro caminho, implicaria no aprofundamento das discussões e melhoria do Documento por meio da busca de efetiva conexão deste com a definição legal de direitos e objetivos de aprendizagem e desenvolvimento. Este segundo caminho, já destacado pelas Conselheiras em várias ocasiões, teriam por centralidade a discussão e retomada dos referenciais das atuais Diretrizes Curriculares, emanadas do CNE, em um desenho pedagógico que permita uma unidade nacional sem prescindir da diversidade, possibilitando que articule direitos e objetivos de aprendizagem e desenvolvimento e, ao mesmo tempo, reforce o protagonismo dos profissionais da educação na elaboração de propostas curriculares das instituições e escolas.” (AGUIAR, 2018, p. 18) 
não se deu por unanimidade ${ }^{2}$ a despeito da condução coercitiva e aligeirada ${ }^{3}$ do processo por parte de muitos integrantes daquela casa: "o CNE abdicado de seu papel de órgão de Estado, subentendendo-se que, tendo renunciado por vontade própria à autonomia que lhe dá a legislação, assumiu função de órgão de governo, apequenando-se, portanto.” (MENDONÇA, 2018, p. 36)

Enquanto processo histórico há que se destacar que a BNCC não foi consensuada, não foi pactuada e, portanto, apresenta vários questionamentos acerca de sua legitimidade. Todavia, está aprovada. Está homologada. Enquanto Política de Governo ela é normativa e implica um esforço das Redes de Ensino, no âmbito público ou privado, de repensar suas Propostas Pedagógicas. Por constituirse como instrumento 'de cima pra baixo e de fora pra dentro', destacamos alguns questionamentos à BNCC homologada. Todavia, reconhecemos que o debate sobre esse processo se apresenta como um instrumento para a construção/ afirmação de outras bases que a Educação precisa reafirmar. Passamos, a partir de agora, a discorrer sobre essas premissas.

\section{O DISCURSO DA MUDANÇA: REDUCIONISMOS E CONTRADIÇÕES}

A epígrafe que abre este texto nos convida a refletirmos sobre a relação que se estabelece entre conhecimento, instituições e poder. Trata de uma epistemologia do conhecimento. Ou seja, a produção de determinado tipo de conhecimento não pode desconsiderar aquilo que é objetivo e subjetivo em torno do tema. Isso, porque nenhum conhecimento está desprovido do significado social que o homem ocupa em relação ao mundo, à sociedade e a si mesmo.

O debate da BNCC precisa explicitar aquilo que representa, dialeticamente, o discurso de determinado projeto retórico reformista (sentido objetivo) e sua apreensão do ponto de vista da adesão e/ou estranhamento (sentido subjetivo) por parte dos diferentes sujeitos na sociedade. Do ponto de vista objetivo, há na BNCC um modelo de educação que retoma os princípios da 'Teoria do Capital Humano', centrado nas finalidades da educação para o processo de

\footnotetext{
2 Posicionaram-se contrárias à aprovação da BNCC as Conselheiras Márcia Angela da Silva Aguiar, Aurina Oliveira Santana e Malvina Tania Tuttman.

3 "As buscas da celeridade na tramitação, sobretudo, das minutas de Parecer e da Resolução, se sobrepuseram ao papel do CNE como órgão de Estado, comprometendo a discussão e eventuais ajustes e contribuições às minutas." (AGUIAR, 2018, p. 13),

4 Por ser dialético, este movimento não se constitui apenas nessas dimensões. Ele encontra ressonâncias internas, também, entre gestores das políticas, quer seja na proposição, quer na implementação.
} 
desenvolvimento humano e econômico: "a reforma do ensino é vista como um mecanismo para alcançar o ressurgimento econômico, a transformação cultural e a solidariedade nacional." (POPKEWITZ, 1997, 21)

As análises de Popkewitz (1997) sobre as bases da reforma educacional americana nos permitem algumas aproximações com o cenário atual no Brasil. Trata-se da afirmação de que "é preciso entender a reforma educacional contemporânea como uma prática política e social.” (Ibidem). Ou seja, o movimento em torno da afirmação de uma Base Nacional Comum Curricular (BNCC) também pode ser considerado determinado tipo de reforma que toma o currículo e o conhecimento como objetos de regulação social e, no caso brasileiro, por meio de reducionismo do processo formativo, ratificado a partir da defesa de um discurso centrado em competências e habilidades que, além de não atender ao horizonte legal do Plano Nacional de Educação (PNE), que advoga direitos e objetivos de aprendizagem e desenvolvimento, é prescritivo e padronizador.

Há em torno da BNCC um forte discurso do governo e dos setores empresariais na mudança: do conhecimento, da escola, do currículo, da aprendizagem, dos alunos, dos professores. Um discurso de responsabilização individual, sobretudo dos professores, pelo sucesso ou fracasso da educação. $\mathrm{O}$ discurso da mudança fortalece a retórica do pacto, do acordo e da "concertación" em torno da BNCC. Todavia, o que se nota é a clara ênfase na estabilidade, na harmonia e na continuação dos acordos institucionais existentes - não na mudança. (POPKEWITZ, 1997). A afirmação do discurso da mudança tenta tornar o movimento da Base como 'instituído e legítimo', assim como se acredita que seus princípios e objetivos sejam 'instituintes' de um novo processo de escolarização: "a ecologia da reforma relaciona-se com os padrões da regulamentação social encontrada na escola.” (POPKEWITZ, 1997, 22) Assim, as

Preocupações gerais sobre a revitalização moral e econômica da nação vêm à tona através dos processos de escolarização, vistos como uma preparação para um paraíso terrestre, materialmente e espiritualmente generoso (...) As atuais reformas enfatizam que o progresso social depende das crianças, da nação e do sistema que as educa. O seu tom religioso e moral eleva a expectativa da reforma, enquanto, ao mesmo tempo, remove da análise as condições que limitam as transformações sociais. (...) a premissa do sonho do futuro perfeito é de que a escolarização deve tornar-se mais eficiente e racional no desenvolvimento daquilo que já é um tema social fundamental, o do indivíduo possessivo. (Idem, 161)) 
A lógica do discurso reformista da Base não pode ser apreendida apenas de 'cima para baixo e de fora para dentro' mas, sim, pela força que opera por 'dentro' e do lugar que ocupam parte de seus idealizadores':

De modo geral, o texto aprovado da BNCC alinha-se a orientações globais assentadas na Estratégia 2020 do Banco Mundial (BM) "Aprendizagem para Todos Investir nos Conhecimentos e Competências das Pessoas para Promover o Desenvolvimento", segundo a qual os sistemas educacionais deveriam ser ressignificados e entendidos como o conjunto de situações e estratégias de aprendizagem ofertadas pelo setor público ou privado (KLEES, 2012 apud ADRIÃO; PERONI, 2018, p. 51)

Portanto, por dentro do movimento de constituição da BNCC está a configuração de um projeto de governo e de poder que toma, pelo conhecimento, novas formas de conhecer, organizar, regular, avaliar e controlar os processos formativos na escola. Os movimentos de regulação, organização e gestão expressam um novo tipo de gerencialismo na educação em que a gestão do currículo se configura como objeto central das Políticas de Governo. Em relação ao gerencialismo na educação, Frigotto (2012) acrescenta a pedagogia das competências como expressão da lógica e filosofia mercantil do conhecimento da escola capitalista:

O Estado, em vez de alargar o fundo público na perspectiva do atendimento a políticas públicas de caráter universal, fragmenta as ações em políticas focais que amenizam os efeitos sem alterar substancialmente as suas determinações. E, dentro dessa lógica, é dada ênfase aos processos de avaliação balizados pelo produtivismo e à sua filosofia mercantil, em nome da qual os processos pedagógicos são desenvolvidos mediante a pedagogia das competências. (FRIGOTTO, 2012, p. 127-128).

A 'Pedagogia das Competências', como pressuposto pedagógico da BNCC, é claramente definida como resultado de acordos entre os 'organismos multilaterais' e suas pautas de reformas educacionais ancoradas nas políticas neoliberais. $O$ movimento em defesa das competências não é algo novo na história da educação. Afirma-se nos princípios defendidos pelos Organismos Internacionais (OCDE, BANCO MUNDIAL, UNESCO, CEPAL). Remonta e retrocede àquilo que já foi criticado pela educação brasileira: a Teoria do Capital Humano (1950) e Conferência Mundial Sobre Educação para Todos Jomtien, Tailândia (1990), em seu documento 'Satisfação das Necessidades Básicas de Aprendizagem (NEBAS)': "as aprendizagens essenciais definidas na BNCC devem

5 De modo particular, destacam-se: "Movimento pela Base Nacional Comum" e "Todos pela Educação”. 
concorrer para assegurar aos estudantes o desenvolvimento de dez competências gerais, que consubstanciam, no âmbito pedagógico, os direitos de aprendizagem e desenvolvimento." (BRASIL, 2017, p. 8)

A pedagogia das competências reafirma o modelo de gestão empresarial de responsabilização individual dos sujeitos frente aos processos de aprendizagem e apropriação do conhecimento. Isto se dá por meio de um duplo movimento: 'centralização curricular e adoção de um modelo de aprendizagem cognitivista': "entendemos que o modelo de competências, vinculado às demandas empresariais, a padronização curricular que retoma a noção de currículo difundida no início do século XX e o acirramento do controle sobre o trabalho do professor, explicitam a BNCC como 'produto' e 'fomento' do gerencialismo." (ZANOTTO; SANDRI, 2018, p. 139)

Neste cenário, é fundamental problematizarmos os limites das concepções de educação, formação e dinâmicas curriculares centradas no gerencialismo e nas competências e habilidades como fundamentos pedagógicos estruturantes à BNCC. Suas bases estão ancoradas nas Necessidades Básicas de Aprendizagem (NEBA) em que o básico é naturalizado como mínimo. Isto significa

As ferramentas essenciais para a aprendizagem (como a leitura e a escrita, a expressão oral, o cálculo, a resolução de problemas), quando os conteúdos básicos de aprendizagem (conhecimentos teóricos e práticos, valores e atitudes), necessários para os seres humanos possam sobreviver, desenvolver plenamente suas capacidades, viver e trabalhar com dignidade, participar plenamente do desenvolvimento, melhorar a qualidade de sua vida, tomar decisões fundamentadas e continuar aprendendo. (WCEFA, 1990, p. 157)

Em contraposição a esse processo reducionista é fundamental enfatizar o 'conhecimento como fundamento pedagógico, reforçar a autonomia dos sistemas, de suas instituições educativas e dos educadores’. O conhecimento é universal. Ele se fundamenta naquilo que é historicamente produzido pela humanidade e ancorado em bases epistêmicas e socialmente relevantes a serem construídas nos sistemas e instituições educativas, a partir de ampla participação, fortalecendo a gestão democrática e, no bojo desta a autonomia das instituições, de seus sujeitos (profissionais da educação e estudantes) e a centralidade conferida ao projeto pedagógico destas instituições, em consonância a proposição de base comum nacional.

Por essa razão, é preciso distinguir a concepção de base comum nacional (defendida pelas associações científicas do campo) e BNCC, uma vez que 
Base comum nacional não é definição nacional de matriz curricular, ou de maneira ainda mais restrita, retomada de currículos mínimos ou dinâmicas similares. Ou seja, trata-se de estabelecimento de diretrizes nacionais para a formação de professores que garantam unidade na diversidade o que não se coaduna à padronização ou rigidez curricular. É preciso considerar, ainda, que tais processos formativos devem extrapolar o horizonte institucional stricto sensu (DOURADO, 2013, p. 377)

\section{REGULAÇÃO DO CONHECIMENTO E DO CURRÍCULO}

Um dos pilares que sustentam a defesa da BNCC é um tipo de conhecimento convertido em conteúdo que pode ser apreendido, medido e avaliado: "a aprendizagem de qualidade é uma meta que o País deve perseguir incansavelmente, e a BNCC é uma peça central nessa direção" (BRASIL, 2017, p. 5) Por serem práticos e utilitários, "os critérios de conhecimento e intervenção são usados para administrar as organizações sociais” (POPKEWITZ, 1997, 27), uma vez que, por meio de abordagem positivista, "o conhecimento é removido das considerações situacionais de tempo e espaço que são uma parte das condições sociais". (Idem, p. 26)

O conhecimento prático requerido nas habilidades e competências da BNCC é aquele marcado pela lógica pragmática, utilitarista e reducionista. É preciso considerar "aquilo que os estudantes devem aprender na Educação Básica, o que inclui tanto os saberes quanto a capacidade de mobilizá-los e aplicá-los." (BRASIL, 2017, p.12). Um conhecimento que traga aos estudantes "o estímulo à sua aplicação na vida real.” (Idem, p. 15)

Essa concepção gerencial e pragmática, se materializada, poderá resultar em matrizes e dinâmicas curriculares mais operacionais e padronizadas, pautadas por uma secundarização das Ciências Humanas e Sociais e das Artes em geral.

O que se observa na BNCC é a defesa de um tipo de procedimento do ato de conhecer e do próprio conhecimento em si a partir de uma lógica instrumental. Os estudos de Miranda (1997), quando a autora afirma a emergência de um novo paradigma de conhecimento na América Latina, deslindam esse processo e sua lógica economicista:

A centralidade do conhecimento (da informação, da produção do conhecimento e de sua difusão) e a implícita mudança da concepção de conhecimento parecem ser uma ideia para a qual convergem todos os discursos, todas as propostas, todos os chamados atores sociais. Afinal, não se pode negar o impacto da globalização, associado à revolução tecnológica, impõe um novo tipo de conhecimento: menos discursivo, mais operativo; menos particularizado, mais interativo, comunicativo; menos intelectivo, mais pragmático; menos setorizado, mais global; não apenas fortemente cognitivo, mas também valorativo. (MIRANDA, 1997, p. 41) 
Segundo Miranda (1997), esse novo padrão de conhecimento utilitarista é apreendido e adquirido mediante a ação (saber fazer), a utilização (saber usar) e a interação (saber comunicar). O conhecimento é orientado por sua operacionalidade, funcionalidade: saber para quê? Sendo assim, "espera-se que o processo de ensinar-aprender seja transformado por essa necessidade de aplicação imediata: apreender fazendo, aprender em serviço, aprender praticando." (Idem, p. 43) O conhecimento vai-se confundindo com a informação e o ato de conhecer vai ficando cada vez mais identificado com os procedimentos de documentação e acesso às informações. Centrado no sujeito e no discurso do processo de "aprender a aprender", a BNCC também vai explicitando suas feições reducionistas.

Há, portanto, na BNCC, uma lógica da reforma e da regulação do conhecimento em que "o problema por trás da mudança é como e por que as formas de verdade vêm a prevalecer e, em pontos diferentes, são historicamente desafiadas." (POPKEWITZ, 1997, 51) Mas de qual conhecimento estamos falando na BNCC? Daquele que deve ser produzido a partir dos currículos também regulados e avaliados.

O currículo na escola "expressa conjuntos de relações sociais e estruturais através dos próprios padrões de comunicação sobre os quais é formulado (...) falar sobre currículo pressupõe, então, um conjunto de suposições e valores sociais que não são claramente aparentes, mas que limitam a gama de escolhas disponíveis." (Idem, 30). Neste sentido, há que se perguntar a partir da BNCC: qual currículo? Para que tipo de homem? Para qual sociedade? O próprio documento nos apresenta pistas do seu modo regulatório: "a Base Nacional Comum Curricular (BNCC) é um documento de caráter normativo que define o conjunto orgânico e progressivo de aprendizagens essenciais que todos os alunos devem desenvolver ao longo das etapas e modalidades da Educação Básica, de modo a que tenham assegurados seus direitos de aprendizagem e desenvolvimento" (BRASIL, 2017, p. 7). Importante ressaltar que a BNCC se restringe a um tipo de aprendizagem: aquela parametrizada e instrumentalizada com ênfase nas operações básicas e na leitura.

O próprio texto da BNCC determina um tipo de currículo normativo em que o conhecimento deve ser apreendido de forma 'orgânica e progressiva'. Aqui reside uma das críticas mais contundentes ao documento: uma ênfase nos processos cognitivistas em que o conhecimento deve ser apreendido gradualmente e parametrizado por bases comuns: "é necessário que sistemas, redes e escolas garantam um patamar comum de aprendizagens a todos os estudantes, tarefa para a qual a BNCC é instrumento fundamental" (Ibidem). Aquilo que a BNCC nomeia como um 'patamar comum de aprendizagem', leia-se conteúdos mínimos: “ao definir quais conhecimentos e habilidades são fundamentais para se aprender em 
cada etapa da Educação Básica, a BNCC funciona como uma prática discursiva que envolve um jogo de prescrições que determina escolhas e, também, exclusões". (CARVALHO; SILVA; DELBONI, 2017, p. 490)

A exigência de estabelecer um currículo comum para o país reafirma a existência de um suposto consenso sobre o que é moral e intelectualmente apropriado e para o que a tarefa da escola é a de apresentar coerência e padronização nos programas escolares, negligenciando, assim, a autonomia pedagógica, os diferentes atores que constroem o cotidiano educacional e escolar. O que se observa é um tipo de regulação do conhecimento e do currículo que opera na retórica da reforma e da descentralização/centralização que, por meio da BNCC, efetiva-se por efetiva avaliação e controle do currículo: “a descentralização é uma estratégia da direção do estado, enquanto que a suposição de consenso está relacionada às exigências de maior padronização". (POPKEWITZ, 1997, p. 165)

Por mais que o discurso e/ou retórica em torno da construção de uma Base defenda a existência de uma parte comum e uma parte diversificada do currículo, o que se nota é a tendência de padronização e homogeneização dos conteúdos, objetivos e habilidades. Aquilo que se anuncia como 'base', poder-se-á converter-se em 'currículo mínimo', particularmente em municípios que nem possuem uma Proposta Pedagógica para as Etapas e Modalidades de ensino. Outro risco, em relação à padronização de uma base, é orientar-se por uma lógica restrita do 'direito à aprendizagem'. Não se trata a ter direito a aprender, mas sim, 'direito à educação', uma vez que aprender é uma condição inerente ao ato educativo. Portanto, falar em direito à educação é mais amplo do que direito à aprendizagem, já que o direito à educação implica uma instituição educativa de qualidade, com professores valorizados, com currículos construídos coletivamente, com infraestrutura adequada que permita a materialização de um projeto político-pedagógico democrático e não apenas restrito às necessidades de aprendizagem.

Aprender é um aspecto fundante desde a origem da ideia de instituições educativas. Todavia, a pergunta a ser feita é: historicamente, esse direito foi concedido a quem? De qual educação falamos? Como concordar com um discurso que diz: a 'Base garantirá os direitos de aprendizagem'. Quais aprendizagens? Aquelas definidas e recortadas por um grupo de pessoas que deverá ser aplicado em todo país? Por uma lógica que diz 'estes direitos de aprendizagem entram na base e outros não?' Quais limites se efetivam ao regular e normatizar o ato de aprender que é universal? 
Há outras possibilidades pedagógicas a serem problematizadas e vivenciadas, a partir de um processo pedagógico que não reduza o direito da educação ao direito da aprendizagem? A esse respeito, Oliveira faz importantes sinalizações:

A pluralidade do Brasil, ao contrário do caminho escolhido pelo governo ao insistir com a BNCC, exige pluralidade de possibilidades, de oferta de trajeto e de garantias de condições para que o processo ensino-aprendizagem ocorra. Para origens diferentes, necessidades diferentes, características sociais, culturais e econômicas diferentes, é preciso oferecer trajetórias diferentes! Tratar igualmente os desiguais é aprofundar a desigualdade! É inferiorizar alguns perante os outros. Reconhecer a necessidade de oferecer possibilidades diversas/plurais de proposta e experiência curricular a alunos diferentes/desiguais é necessário para promover a equalização social e a redução das desigualdades (...) Quando escolhemos o que entra nos currículos, escolhemos o que sai e esta decisão é política, favorece a alguns e prejudica outros. No caso brasileiro, vem sendo tomada em prejuízo das questões sociais, da formação crítica, da cidadania, do direito que se diz estar defendendo. (OLIVEIRA, 2018, p. 57)

Os processos que orientam a política do currículo na BNCC alinham outra dimensão que lhe é constitutiva: a articulação entre 'regulação e avaliação'. Essa dimensão ganha centralidade quando se regula o que vai ser ensinado, regula-se como vai ser implementado e acompanhado, regula-se a formação de professores, regulam-se os livros didáticos que serão distribuídos a partir da Base, avaliam-se os cursos de formação de professores e seus currículos e Diretrizes, avaliam-se os professores, avaliam-se os estudantes: "a BNCC (...) além dos currículos, influenciará a formação inicial e continuada dos educadores, a produção de materiais didáticos, as matrizes de avaliações e os exames nacionais, que serão revistos à luz do texto homologado da Base.” (BRASIL, 2017, p. 5)

Como política estruturante, "a BNCC integra a política nacional da Educação Básica e vai contribuir para o alinhamento de outras políticas e ações, em âmbito federal, estadual e municipal, referentes à formação de professores, à avaliação, à elaboração de conteúdos educacionais" (BRASIL, 2017 p. 8) Esse alinhamento objetiva garantir condições para que se implemente no país um processo de avaliação estandardizado marcado pelo reducionismo, pelo controle e pela ênfase no controle dos resultados.

Para Saviani (2016), o alinhamento entre BNCC e avaliação em larga escala indica novos parâmetros para a organização e o funcionamento do ensino e do currículo em todo o país: 
Considerando a centralidade que assumiu a questão da avaliação aferida por meio de testes globais padronizados na organização da educação nacional e tendo em vista a menção a outros países, com destaque para os Estados Unidos tomados como referência para essa iniciativa de elaborar a "base comum nacional curricular" no Brasil, tudo indica que a função dessa nova norma é ajustar o funcionamento da educação brasileira aos parâmetros das avaliações gerais padronizadas. Essa circunstância coloca em evidência as limitações dessa tentativa, pois, como já advertimos, essa subordinação de toda a organização e funcionamento da educação nacional à referida concepção de avaliação implica numa grande distorção do ponto de vista pedagógico (SAVIANI, 2016, p.75).

A evidência dos processos de regulação e avaliação no documento da Base pode ser facilmente identificada quando se observa a correlação entre competências e habilidades, que devem ser averiguadas por meio de objetivos comportamentais dos alunos. A codificação de descritores que identificam os objetivos de aprendizagem, cobrados nos conteúdos do processo de avaliação estandardizado, contribui para as estratégias de regulação do ensino e da aprendizagem e, portanto, para a implementação de um currículo formal centralizado (MACEDO, 2018, p. 32).

\section{POR PROCESSOS MAIS AUTÔNOMOS}

Dentre os diferentes discursos e/ou retóricas que sustentam a ideia da BNCC e de uma avaliação nacional, estão aqueles que tratam a desigualdade social como processo de equidade. A primeira tem suas bases no modo de produção desigual e combinado e a partir da dialética inclusão-exclusão. A crítica à desigualdade social é uma tarefa da educação democrática e emancipatória. A segunda mascara e vela a desigualdade sem procurar alterá-la. Nessa lógica, é necessário ajustar os desajustados e contribuir para que o modelo econômico produza o 'menor efeito possível'. É a partir dessa última que a BNCC firma seus princípios enfatizando o seu foco na equidade.

$\mathrm{Na}$ contramão desses pressupostos, é fundamental reafirmar que os processos de regulação e avaliação precisam ser redefinidos à luz de uma Política de Estado, com ampla participação, assegurando o regime de colaboração entre os entes federados e suas autonomias. Opondo-se à mera transmissão de informações, da preparação para o mercado de trabalho e adaptação à realidade, a educação precisa compreender o humano como sujeito capaz de pensar, de dialogar, de interagir, enfim, de construir conhecimentos. Nessa direção é fundamental retomar o princípio constitucional da educação para a cidadania. 
As ações e os objetivos da educação devem convergir para uma formação emancipadora, portanto, como prática social. Tal compreensão, ratifica o direito à educação, não circunscrito à aprendizagem instrumental, ao reafirmar os princípios da produção/socialização do conhecimento histórico-socialmente construído aos processos de formação e humanização do homem.

Sendo assim, destaca-se a necessidade de debates críticos em torno das Políticas Educacionais a fim de que contribuam para a consolidação de uma nação soberana, democrática, justa, inclusiva, que promovam a emancipação dos indivíduos e grupos sociais. Essas políticas precisam reconhecer e valorizar a diversidade. Isso significa a concepção ampla de conhecimento, formação e currículos a partir da indissociável relação entre educação e cultura.

A cultura, fruto da ação humana, é compreendida no tempo, no espaço e se concretiza na produção material e imaterial. Portanto, não há como separar as condições 'políticas, culturais e materiais'.

Uma educação comprometida com a produção e disseminação do conhecimento requer a garantia de projetos e percursos formativos emancipatórios, expressos por dinâmicas curriculares que garantam a formação como expressão do direito social e subjetivo das crianças, adolescentes, jovens e adultos, por meio de postura radical contra todas as formas de exclusão social. Todavia, essa consideração só se concretiza quando se tem claro que qualquer processo de inclusão social requer, antes de tudo, a superação da desigualdade social. Assim, o discurso de defesa da BNCC no combate à desigualdade social/ educacional é insuficiente para garantir o princípio da igualdade na educação e poderá converter-se em processo gerencial de naturalização das desigualdades e diferenças.

\section{REFERÊNCIAS}

ADRIÃO, Theresa; PERONI, Vera. A formação das novas gerações como campo para negócios? In: AGUIAR, M.A.S.; DOURADO, L.F. (Orgs.). A BNCC na contramão do PNE 2014-2024: avaliação e perspectivas. [Livro Eletrônico]. - Recife: ANPAE, 2018.

AGUIAR, Márcia Angela da S. Relato da resistência à instituição da BNCC pelo Conselho Nacional de Educação mediante pedido de vista e declarações de voto. In: AGUIAR, M.A.S.; DOURADO, L.F. (Orgs.). A BNCC na contramão do PNE 2014-2024: avaliação e perspectivas. [Livro Eletrônico]. - Recife: ANPAE, 2018. 
BRASIL, Ministério da Educação. Secretaria de Educação Básica. Base Nacional Comum Curricular: educação é a base. 2017.

BRASIL, Lei n. 13.005, de 25 de junho de 2014. Aprova o Plano Nacional de Educação PNE e dá outras providências. Diário Oficial da União, Brasilia, DF, 2014.

BRASIL. Ministério da Educação. Secretaria de Educação Básica. Secretaria de Educação Continuada, Alfabetização, Diversidade e Inclusão. Conselho Nacional da Educação. Diretrizes Curriculares Nacionais Gerais da Educação Básica/ Ministério da Educação. Secretária de Educação Básica. Diretoria de Currículos e Educação Integral. - Brasília: MEC, SEB, DICEI, 2013.

CARVALHO, Janete Magalhães; SILVA, Sandra Kretli da; DELBONI, Tânia Mara Zanotti Guerra Frizzera. A base nacional comum curricular e a produção biopolítica da educação como formação de "capital humano". In: Revista e-Curriculum, São Paulo, v.15, n.2, p. 481 - 503 abr./jun. 2017

AGUIAR, M.A.S.; DOURADO, L.F. (Orgs.). A BNCC na contramão do PNE 2014-2024: avaliação e perspectivas. [Livro Eletrônico]. - Recife: ANPAE, 2018.

DOURADO, Luiz Fernandes; OLIVEIRA, João Ferreira de.; Base Nacional Comum Curricular (BNCC) e os impactos nas políticas de regulação e avaliação da educação superior. In: AGUIAR, M.A.S.; DOURADO, L.F. (Orgs.) A BNCC na contramão do PNE 2014-2024: avaliação e perspectivas. [Livro Eletrônico]. - Recife: ANPAE, 2018.

DOURADO. Luiz Fernandes. A formação de professores e a base comum nacional: questões e proposições para o debate. RBPAE - v. 29, n.2, p. 367-388, mai/ago. 2013

FRIGOTTO, Gaudêncio. Os circuitos da história e o balanço da educação no Brasil na primeira década do século XXI. In: CIAVATTA, Maria (Org.) Gaudêncio Frigotto: um intelectual crítico nos pequenos e nos grandes embates. Belo Horizonte : Autêntica Editora, 2012.

IANNI, Octavio. A dialética da globalização. In: Teorias da globalização. Rio de Janeiro: Civilização Brasileira, 2004. 
MACEDO, Elizabeth. "A base é a base". E o currículo o que é? AGUIAR, M.A.S.; DOURADO, L.F. (Orgs.) A BNCC na contramão do PNE 2014-2024: avaliação e perspectivas. [Livro Eletrônico]. - Recife: ANPAE, 2018.

MENDONÇA, Erasto Fortes. PNE e Base Nacional Comum Curricular (BNCC): impactos na gestão da educação e da escola. In: AGUIAR, M.A.S.; DOURADO, L.F. (Orgs.) A BNCC na contramão do PNE 2014-2024: avaliação e perspectivas. [Livro Eletrônico]. - Recife: ANPAE, 2018.

MIRANDA, M.G. Novo paradigma do conhecimento e políticas educacionais na América Latina. Cadernos de Pesquisa, São Paulo, n. 100, p. 49-56, mar. 1997.

OLIVEIRA, Inês Barbosa de. Políticas curriculares no contexto do golpe de 2016: debates atuais, embates e resistências. In: AGUIAR, M.A.S.; DOURADO, L.F. (Orgs.) A BNCC na contramão do PNE 2014-2024: avaliação e perspectivas. [Livro Eletrônico]. - Recife: ANPAE, 2018.

POPKEWITZ, Thomas S. Reforma Educacional: por uma leitura sociológica Poder e conhecimento em Educação. Trad. Beatriz Affonso Neves, Porto Alegre : Artes Médicas, 1997.

SAVIANI, Dermeval. Educação Escolar, Currículo e Sociedade: o problema da Base Comum Curricular. Movimento: Revista de Educação. Faculdade de Educação - Programa de Pós-Graduação em Educação. Universidade Federal Fluminense. Ano 3. n. 4. 2016.

WCEFA. Satisfacción de las necessidades básicas de aprendizaje: una visión para el decênio de 1990. Santiago, UNESCO-OREALC, 1990. [Documento de Referência, Conferência Mundial sobre Educación para todos, Jomtien, Tialância, 5-7 março de 1990)

ZANOTTO, Marijane; SANDRI, Simone; Avaliação em larga escala e Bncc: estratégias para o gerencialismo na educação. IN: Temas \& Matizes, Cascavel, v. 12, n. 23, p. 127 - 143, jul./dez. 2018. 
LUIZ FERNANDES DOURADO é Professor Titular Emérito da Universidade Federal de Goiás, Doutor em Educação pela Universidade Federal do Rio de Janeiro, pós-doutorado em Sociologia na École des Hautes Études en Siences Sociales (EHESS). Diretor de Intercâmbio Institucional da Anpae. E-mail: luizdourado1@gmail.com

ROMILSON MARTINS SIQUEIRA é Diretor da Escola de Formação de Professores e Humanidades da PUC Goiás. Pós-Doutorando pela Programa de Pós-Graduação em Educação da UFG, supervisão do professor Luiz Dourado. Doutor em Educação pela Faculdade de Educação da UFG. E-mail: romilsonmartinsiqueira@hotmail.com

ORCID: https://orcid.org/0000-0002-6878-9373

Recebido em julbo de 2019

Aprovado em julho de 2019 